\title{
Special issue on accessibility and software design for all
}

\author{
João Barroso ${ }^{1} \cdot$ Lourdes Moreno Lopez $^{2} \cdot$ Hugo Paredes $^{1} \cdot$ Franz Puehretmair $^{3} \cdot$ Tania Rocha $^{1}$
}

Published online: 8 July 2019

(c) Springer-Verlag GmbH Germany, part of Springer Nature 2019

Ethical, legal and even economics arguments urge concerning Universal Access to the Information and Communication Technologies (ICT). The ethical principle of digital inclusion states that all individuals have the same fundamental right to access and use, with safety and comfort, systems, products and services that are integrated in digital environments. From a legal perspective, inclusive products, services and environments create more balanced and equitable communities, with more autonomous and productive individuals. Furthermore, economics arguments suggest that the development of inclusive services, products or environments increases the number of potential users.

Therefore, as a mean to improve the quality of people's life, the development of accessible and usable systems, products and services is mandatory. Digital environments, with all advantages that they can provide, such as endless services and products just "one click away", cannot be inaccessible for any group of users. However, there are still specific groups of individuals excluded from the benefits of ICTs, as they face accessibility and usability glitches (in access and interaction) difficult to overcome.

In this context, digital accessibility and usability became key topics for ICT development. Raising awareness and adding responsibility to develop accessible and usable product

Tania Rocha

trocha@utad.pt

João Barroso

jbarroso@utad.pt

Lourdes Moreno Lopez

lmoreno@inf.uc3m.es

Hugo Paredes

hparedes@utad.pt

Franz Puehretmair

franz.puehretmair@ki-i.at

1 INESC TEC and University of Trás-os-Montes e Alto Douro, Vila Real, Portugal

2 Universidad Carlos III de Madrid, Madrid, Spain

3 KI-I, Linz, Austria or service that can assist users to perform effective, efficient and satisfactory tasks regardless of their capabilities or abilities, the environment and situation or the equipment used for interaction is a contemporary imperative.

Accessibility can be achieved through the application of universal design principles, as well as through the development (design, implementation and evaluation) of products and services (including assistive technologies) that can cover the needs of different populations, by adapting existing products and creating alternative means of information and/or communication.

In this field of study, this UAIS Special Issue entitled The Accessibility and Software Design for All collects research work presented at the 7th International Conference on Software Development and Technologies for Enhancing Accessibility and Fighting Info-exclusion (DSAI 2016), which was held at the University of Trás-os-Montes e Alto Douro (UTAD), Vila Real, Portugal. Six (6) papers were selected, focusing on accessible and usable interfaces and interaction, assistive technologies, case studies, models and techniques for info-exclusion and ageing, taking into account the target audience of the UAIS Journal.

The first contribution, by Dias et al. "On modelling the quality of concept mapping towards more intelligent online learning feedback: A fuzzy logic-based approach", presents a model, entitled Fuzzy Inference System (FIS) Concept Mapping (FISCMAP), involving "modelling techniques as a vehicle to improve the intelligence of an online learning feedback environment that could promote personalization and adaptation to the student's online educational needs". Authors used CMapTool as the online environment that captures the students' actions and choices during concept mapping construction, and eight (8) CMapTool measurements were considered to form inputs to a five-level FIS, equipped with 115 expert's fuzzy rules. Experimental results have shown that the FISCMAP scheme proposed can provide intelligent descriptors regarding the students' online concept mapping and the FISCMAP's dynamic analysis of concept mapping quality and identification of the students' transitional step behaviour, provide further insight into the 
CM building strategies they adopt, forming constructive feedback.

In their paper "Cultural Heritage Visits Supported on Visitors' Preferences and Mobile Devices" Rodrigues et al. propose a mobile application to explore monuments, museums and cities. The application sets an itinerary where users can move at their own pace and have all the complementary information needed about each of the points of interest. The application includes an adaptive user interface where routing and augmented reality are connected to acknowledge the needs of different user's categories, such as elders, kids, experts or general users.

In their contribution "Validation of a Usability Assessment Instrument According to the Evaluators Perspective about the Users' Performance", Martins et al. present the ICF-based Usability Scale (ICF-US) to evaluate the usability of technologies for ageing in place. To that purpose, they performed two (2) observational studies involving 184 participants to assess the validity and reliability of the ICF-US, to evaluate the usability according the evaluators' perspective about the users' performance; and to verify the utility and applicability of the ICF-US.

Heumader et al. explore "Self-Determined Easy Access to Different Literacy Levels" by describing an app that allows creating and managing simplifications of complex information that enable users to read information adapted to their individual reading skills. The app "maps a three-step process of translation including stakeholders located at different institutions on a CMS, which provides information of scalable complexity in terms of language level and level of detail".

Kozuh and Debevc present "The Utilisation of Social Media among Users with Hearing Loss: An Analysis of Facebook Communities". They aimed at examining how social media communities are being accessed, created and maintained by d/Deaf and hard of hearing users by examining 133 social media communities of the $d /$ Deaf and hard of hearing from three main aspects: relational, substantive and technical aspects. Furthermore, their analysis includes the size, strength, organization and content of communities, members' communication and accessibility of the platform, as well as its availability, attention and response indicators.

In the paper "Publishing accessible proceedings: the DSAI 2016 case study", Ribera, Pozzobon and Sayago discuss methods and technical procedures and present steps necessary in authoring, conversion and validation to turn original articles of the DSAI 2016 proceedings, in MS Word and LaTeX formats, into accessible PDFs. As result, papers of DSAI 2016 were published in accessible format using MS Word plus PDF Axes plus PDF Accessibility checker and the authors recommend "the need to include a new role in the organizing committee of conferences for dealing with accessible publishing".

In conclusion, the six (6) contributions presented in this special issue settle the importance of accessible and usable ICT in people's life, especially people with disabilities and the elderly. The development of solutions that fulfil user's needs and expectations, the roll of assistive technologies and the technological opportunities in the universal access research area are topics that the guest editors have tried to highlight in the selected papers.

The guest editors would like to thank all the reviewers for their valuable input, as well as the authors, who at all times pursued the best quality for their work. Special thanks to Constantine Stephanidis and Margherita Antona, Editors in-Chief of the Universal Access in the Information Society journal, for their guidance and all the help during the preparation of this issue.

\section{List of reviewers}

Andre Sousa

Andreas Holzinger

Antonio Pereira

April Yorke

Barbara Leporini

Brian Wentz

Frode Eika Sandnes

Iosif Klironomos

Jaime Muñoz Arteaga

Julio Abascal

Manuel Pérez-Cota

Maryann Demchack

P.L. Patrick Rau

Ravi Kuber

Simeon Keates

Sofia Dias

Vasileios Charisis

Vitor Santos

Publisher's Note Springer Nature remains neutral with regard to jurisdictional claims in published maps and institutional affiliations. 